\title{
VARIAÇÕES MORFOLÓGICAS E VOLUMÉTRICAS ASSOCIADAS À INCIDÊNCIA DE SISTEMAS FRONTAIS EM DUAS PRAIAS ARENOSOS DO LITORAL PARANAENSE CLÉCIO JOSÉ LOPES DE QUADROS*
}

\author{
DISSERTAÇÃO DE MESTRADO - Programa de Pós-Graduação em Geologia - UFPR \\ DATA DE DEFESA: 18 out. 02
}

\begin{abstract}
O objetivo deste trabalho foi contribuir para a compreensão da dinâmica costeira e, conseqüentemente, fornecer subsídios para o planejamento ocupacional e manejo de alguns setores da orla litorânea do estado do Paraná. Para contribuir com a compreensão da dinâmica costeira, foi efetuada a caracterização da morfologia e dinâmica de duas praias arenosas, correlacionando-as com a incidência de sistemas frontais sobre a região. $A$ acentuada agitação marítima que acompanha o trajeto percorrido por alguns sistemas frontais apresenta-se como o maior regulador da dinâmica costeira do Sul do Brasil, sendo que os efeitos sentidos pela orla em decorrência de tais fenômenos podem tornar-se problemas quando estes atingem áreas ocupadas. A caracterização das praias foi realizada através de doze levantamentos planialtimétricos mensais, em duas praias, salvo meses em que não puderam-se realizar as amostragens
\end{abstract}

em decorrência de problemas técnico - operacionais. Estes perfis foram amostrados na zona emersa e submersa das praias, sendo utilizado para esta última, um método desenvolvido e apresentado na dissertação em forma de artigo na íntegra. Com o auxilio dos Boletins de Sistemas Frontais e Boletins de Eventos Notórios - Casos de Agitação Marítima de Grande impacto na América do Sul, disponibilizados pela página do Sistema de Previsão de Ondas- INPEC/CPTEC, foi possível efetuar um levantamento da incidência e freqüência destes eventos. Com base nos resultados obtidos, foram apresentadas algumas sugestões e recomendações com objetivo de incentivar trabalhos referentes a este tema, o que, em um futuro próximo, poderia minimizar os problemas decorrentes da interação entre dinâmica e ocupação antrópica da orla, problemas estes que se tornaram comuns no litoral do estado do Paraná. 